\title{
The study of oxidative status in children with end stage renal disease on regular hemodialysis
}

\author{
Ahmed Mohamed Mahmoud Odima ${ }^{1}$, Nagy Mohamed Abo Elhana ${ }^{1}$, Wesam Salah Mohamed ${ }^{2}$ and \\ Mohamed Abd Elaziz Elgamsy ${ }^{1}$. \\ Department of Pediatric Medicine ${ }^{1}$ and Department of Clinical Pathology ${ }^{2}$, Faculty of Medicine, Tanta \\ University, Egypt. \\ Corresponding author: Ahmed Mohamed Mahmoud Odima; Mobile: 01008869083; Email: ahmedodeama2000@gmail.com
}

\begin{abstract}
Background: Oxidative stress has long been demonstrated in haemodialysis patients. However, the factors influencing their oxidative status have not been characterized extensively in these patients. Despite heterogeneity in the oxidative stress levels in the CKD population, there has been little effort to measure patient oxidative stress levels before the use of any anti-oxidant therapies to optimize outcome.

Objectives: Assessment of oxidative stress and the effects of using antioxidant medications on oxidative status in children with end stage renal disease under regular hemodialysis.

Subjects and Methods: 70 children were included in this study and were categorized into 2 groups: Group (1): 35 children with ESRD on regular haemodialysis. Their ages ranged from 8 to 15 years old. They were 14 males and 21 females. All patients were undergoing haemodialysis three times per week, with each dialysis session lasting for three to four hours. Group (2): 35 healthy children with matched age and sex that were serving as control group. All patients were receiving antioxidant drugs regularly for 3 months. These antioxidant drugs were vitamin $\mathrm{E}$ in a dose of $5 \mathrm{mg} / \mathrm{kg} /$ day, vitamin $\mathrm{C}$ in a dose of 100-200 $\mathrm{mg} /$ day, N-Acetyl Cysteine in a dose of one sachet $(200 \mathrm{mg})$ twice daily with meal. All children in both groups were subjected to: (a) complete history taking. (b) Full clinical examination. (c) Laboratory Investigations [Routine Investigations: $C B C$, blood urea, serum creatinine and BUN, PTH and PT, PTT and Bleeding Time. Specific Investigations: Measuring levels of 1-Interleukin-1 $\beta$, tumor necrosis factor alpha, thiobarbituric acid reactive substances and malondialdehyde].

Results: There was an increase in markers of oxidative stress in children with end-stage renal disease on regular haemodialysis in the form of: 1) Increase serum level of interleukin $1 \beta$ (IL-1 $\beta$ ). 2) Increase serum level of tumor necrosis factor alpha (TNF- $\alpha)$. 3) Increase serum level of thiobarbituric acid reactive substances (TBARS). 4) Increase serum level of malondialdehyde (MDA). These levels were decreased with antioxidant drugs used in this study.

Conclusion: The high levels of oxidative stress markers were decreased after regular therapy by antioxidant medications for 3 months in the form of vitamin E (5 mg/kg/day), vitamin C (100-200 mg /day) and N-Acetyl Cysteine (one sachet (200 mg) twice daily with meal).

Key words: Oxidative status: End stage renal disease; Hemodialysis.
\end{abstract}

\section{INTRODUCTION}

ESRD represent the state in which a patient's renal dysfunction has progressed to the point at which homeostasis and survival can no longer be sustained with native kidney function and maximal medical management. At this point renal replacement therapies (dialysis or renal transplantation) become necessary ${ }^{(1)}$. Data from the United States Renal Data System (USRDS) revealed that in patients younger than 20 years old of age, the annual incidence of ESRD increased marginally from 13 per million in 1988 to 15 per million in $2003^{(2)}$.

The etiology of CKD in Egyptian children less than 5 years of age was comprised of parenchymatous disease in $73 \%$ of cases and obstructive etiology in $27 \%$ of cases, while after 5 years of age parenchymatous disease was $67 \%$ and obstructive etiology accounted for $33 \%$ of cases, this was explained by the possible abuse of nephrotoxic antibiotic in young infants and children ${ }^{(3)}$.

A compound becomes a free radical by 
either gaining an additional electron or by losing one. The unpaired electron generally increases the chemical reactivity of the atom or molecule because the atom attempts to abstract electrons from outer organic molecules in order to pair the odd electron. The extreme reactivity of oxygenfree radicals renders them capable of damaging molecular species common to all cells and tissues. A system of nutritional and endogenous enzymatic antioxidant defenses generally holds the production of free radicals in check, thus preventing "oxidant stress" and subsequent tissue damage ${ }^{(4)}$.

An evidence suggests that oxidant stress may contribute to mitochondrial swelling (mitochondrial membrane permeability transition) that precedes cell death. The presence of low concentrations of $\mathrm{H}_{2} \mathrm{O}_{2}$ has been shown to activate the transcription factor, NF-kappa $\mathrm{B}$, which can then enter the nucleus of cells, bind to DNA control elements/ and induce synthesis of specific mRNAs (5). Animal experiments have provided sample evidence that ROS play a major role in many glomerular diseases. Most of this evidence has been obtained indirectly by the detection of products of lipid peroxidation in renal tissues and by the demonstration of protective effects of administered antioxidants ${ }^{(6)}$.

Oxidative stress has been demonstrated in human patients with nephritic syndrome. Because the direct quantification of reactive oxygen species is not feasible, most studies have shown increased levels of lipid peroxidation by-products, particularly malonyl di-aldehyde (MDA), in serum or erythrocytes or both ${ }^{(7)}$. The body antioxidant defenses are endogenous and exogenous (dietary and therapeutic). Dietary antioxidants include vitamin $\mathrm{E}$, vitamin $\mathrm{C}$ (L-ascorbic acid), and $\beta$ carotene. Vitamin $\mathrm{E}$ refers to eight structurally similar compounds, $\alpha-, \beta-, \gamma-$, and $\Delta$ tocopherol. The $\alpha$-tocopherol has the highest biological activity and is therefore often referred to as vitamin $\mathrm{E}$. The $\alpha$-tocopherol and $\beta$ carotene are lipid-soluble molecules, whereas vitamin $\mathrm{C}$ resides in the aqueous phase. Importantly, many antioxidants exhibit synergistic relationships with other antioxidants; for example, vitamin $\mathrm{C}$ is capable of recycling $\alpha$-tocopherol ${ }^{(\mathbf{8})}$.

\section{PATIENTS AND METHODS}

This present study was carried out at Pediatric Department, Tanta University Hospital over one year [July 2016 - April 2017]. It was approved by the Ethical Committee of the Faculty of Medicine, Tanta University. A total of 70 children were included in this study and were categorized into 2 groups: Group (1) comprised of 35 children with ESRD on regular haemodialysis. Their ages ranged from 8 to 15 years old. They were 14 males and 21 females. All patients were undergoing haemodialysis three times per week, with each dialysis session lasting for three to four hours. Group (2) included 35 healthy children with matched age and sex that were serving as control group.

Dialysis was started when GFR is equal or less than $15 \mathrm{ml} / \mathrm{min}$. $/ 1.73 \mathrm{~m} 2$. Patients were dialyzed on Fresenius 4008- B dialysis machine (Germany) at blood flow rate $=2.5 \mathrm{x}$ weight $(\mathrm{kg})+$ $100 \mathrm{ml} / \mathrm{min}$., using polysulphane hollow fiber dialyzers suitable for the surface area of the patients (Fresenius $F 3=0.4 \mathrm{~m} 2, F 4=0.7 \mathrm{~m} 2, F 5$ $=1.0 \mathrm{~m} 2$ and $F 6=1.2 \mathrm{~m} 2$ ). Bicarbonate dialysis solutions were used. All patients were receiving supportive therapy in the form of SC. erythropoietin in a dose of $50 \mathrm{IU} / \mathrm{Kg} / \mathrm{session}$, IV iron dextran $76-\mathrm{mg} / \mathrm{Kg} / \mathrm{week}$, oral folic acid 1 $\mathrm{mg} /$ day, oral calcium $1000 \mathrm{mg} /$ day, oral vitamin D (one alpha) in a dose of $0.01-0.05 \mu \mathrm{g} / \mathrm{Kg}$ / day and oral antihypertensive medications for hypertensive patients.

All patients were receiving antioxidant drugs regularly for 3 months. These antioxidant drugs were vitamin $E$ in a dose of $5 \mathrm{mg} / \mathrm{kg} /$ day, vitamin $\mathrm{C}$ in a dose of $100-200 \mathrm{mg} /$ day and NAcetyl Cystiene in a dose of one sachet $(200 \mathrm{mg}$ ) twice daily with meal (Coombes \& Fassett 2012) (9).

All children in both groups were subjected to: (a) complete history taking including [duration of dialysis and regular drug taking]. (b) Full clinical examination. (c) Laboratory Investigations [Routine Investigations: Complete blood picture $(C B C)$, blood urea, serum creatinine and BUN, PTH and PT, PTT and Bleeding Time. Specific Investigations: Measuring levels of 1-Interleukin$1 \beta$, tumor necrosis factor alpha, thiobarbituric acid reactive substances and malondialdehyde].

\section{Blood sampling:}

Venous blood samples were taken immediately before hemodialysis session at the first dialysis session of the week and before heparin administration. Samples were drawn in tubes with EDTA. Samples were centrifuged at $1000 \mathrm{x}$ g for 15 minutes. The serum was analyzed immediately or aliquot and stored at -20 . 
All patients and controls were subjected to the following investigations:

(A) Routine Investigations: [Complete blood picture, Blood urea, serum creatinine, BUN, PTH, PT, PTT and Bleeding Time].

(B) Specific: Measuring levels of [Interleukin-1 $\beta$, Tumor necrosis factor alpha, Thiobarbituric acid and Human Malondialdehyde by ELISA (Enzyme-Linked Immuno-sorbant Assay technique].

\section{Statistical analysis}

In addition to the descriptive data, statistical analysis was done using IBM SPSS STATISTC VERSION 20
PROGRAM. Data were expressed as mean $\pm \mathrm{SD}$ and analyzed using the Chi square (x2) test and the Anova test to assess the significance of difference in the levels between different parameters. $P<0.05$ was accepted as significant. Coefficient (r) of two variables was also done by using Pearson Correlation Coefficient (r) with $\boldsymbol{P}$ Value Calculation.

\section{RESULTS}

Laboratory assessments of the measured parameters in the different submitted groups are presented in the following tables and figures:

- As regard to routine laboratory data, patients have significant lower values in HB, TLC, platelets count and serum albumin than control group while patients have significant higher values in serum creatinine, blood urea, BUN, PTH, PT and PTT than control group (table 1).

Table (1): Routine laboratory data of studied patients and controls

\begin{tabular}{|c|c|c|c|c|c|}
\hline & \multicolumn{2}{|c|}{ Groups } & \multirow[b]{2}{*}{$\mathbf{t}$} & \multirow[b]{2}{*}{ P-value } \\
\hline & & Patients & Control & & \\
\hline HB (g/dl) & Mean \pm SD & $8.837 \pm 0.964$ & $12.203 \pm 0.510$ & -18.264 & $<0.001 *$ \\
\hline TLC $\left(x^{3} 0^{3}\right.$ per $\left.\mathrm{cmm}\right)$ & Mean \pm SD & $6.353 \pm 1.298$ & $9.446 \pm 2.807$ & -5.043 & $<0.001^{*}$ \\
\hline $\begin{array}{c}\text { Platelets }\left(\mathrm{x10}^{9} \text { per }\right. \\
\text { liter })\end{array}$ & Mean \pm SD & $213.286 \pm 10.235$ & $249.143 \pm 18.479$ & -2.137 & $0.036^{*}$ \\
\hline S. Creatinine (mg/dl) & Mean \pm SD & $7.854 \pm 2.761$ & $0.520 \pm 0.196$ & 15.623 & $<0.001^{*}$ \\
\hline Blood Urea (mg/dl) & Mean \pm SD & $187.571 \pm 54.220$ & $18.629 \pm 2.777$ & 18.410 & $<0.001^{*}$ \\
\hline BUN (mg/dl) & Mean \pm SD & $74.400 \pm 34.641$ & $7.671 \pm 0.962$ & 11.392 & $<0.001^{*}$ \\
\hline Serum Albumin (g/dl) & Mean \pm SD & $2.691 \pm 0.276$ & $4.211 \pm 0.514$ & -15.407 & $<0.001^{*}$ \\
\hline PTT (sec) & Mean \pm SD & $37.514 \pm 8.813$ & $33.457 \pm 7.370$ & 2.089 & $0.040^{*}$ \\
\hline PT (sec) & Mean \pm SD & $14.983 \pm 4.542$ & $12.823 \pm 1.508$ & 2.670 & $0.009 *$ \\
\hline PTH (pg/ml) & Mean \pm SD & $350.256 \pm 231.583$ & $45.486 \pm 11.736$ & 7.776 & $<0.001^{*}$ \\
\hline
\end{tabular}

Abbreviations; $\mathbf{H B}=$ haemglobin, $\mathbf{T L C}=$ total leucocytic count, $\mathbf{B U N}=$ blood urea nitrogen, $\mathbf{P T T}=$ activated partial thromboblastin time, $\mathbf{P T}=$ prothrombin time, $\mathbf{P T H}=$ parathyroid hormone, $\mathbf{t}=$ student test .

- There were no statistically significant differences between the systolic blood pressure and diastolic blood pressure in the studied patients before and after giving antioxidant drugs(p- value $>0.05$ ) but there were significant increase in the systolic and diastolic blood pressure of patients before and after giving drugs when compared with controls(p-value<0.001) (table 2).

Table (2): Blood pressure of studied patients and controls

\begin{tabular}{|c|c|c|c|c|}
\hline \multicolumn{2}{|c|}{ Patients } & \multirow{2}{*}{ Control } & \multicolumn{2}{c|}{ ANOVA } \\
\cline { 5 - 5 } $\begin{array}{c}\text { Before } \\
\text { antioxidant drugs }\end{array}$ & $\begin{array}{c}\text { After } \\
\text { antioxidant } \\
\text { drugs }\end{array}$ & $\begin{array}{c}\text { F } \\
\text { test }\end{array}$ & value \\
\hline
\end{tabular}


The study of oxidative status in children with....

\begin{tabular}{|c|c|c|c|c|c|c|}
\hline SBP & Mean \pm SD & $124.000 \pm 10.901$ & $\begin{array}{c}123.571 \pm \\
15.977\end{array}$ & $\begin{array}{l}115.143 \pm \\
10.675\end{array}$ & 5.367 & $0.006^{*}$ \\
\hline \multirow{3}{*}{$\begin{array}{c}\text { Paired } \\
\text { Samples } \\
\text { Test }\end{array}$} & $t$ & \multicolumn{2}{|c|}{0.140} & & & \\
\hline & P-value & \multicolumn{2}{|c|}{0.889} & & & \\
\hline & Mean \pm SD & $81.143 \pm 9.632$ & $\begin{array}{l}76.000 \pm \\
10.901\end{array}$ & $\begin{array}{l}73.714 \pm \\
10.596\end{array}$ & 4.693 & $0.011^{*}$ \\
\hline \multirow{2}{*}{$\begin{array}{c}\text { Paired } \\
\text { Samples } \\
\text { Test }\end{array}$} & $\mathbf{t}$ & \multicolumn{2}{|c|}{2.240} & & & \\
\hline & P-value & \multicolumn{2}{|c|}{0.072} & & & \\
\hline
\end{tabular}

Abbreviations; $\mathbf{S B P}=$ systolic blood pressure, $\mathbf{D B P}=$ diastolic blood pressure, $\mathbf{S D}=$ standard deviation, $\mathbf{t}=$ student test.

- Specific laboratory data of studied patients and controls with significant p value $<0.001$ for all ( table 3 ).

Table (3): Specific laboratory data of studied patients and controls

\begin{tabular}{|c|c|c|c|c|c|c|}
\hline & \multicolumn{2}{|c|}{ Patients } & \multirow[t]{2}{*}{ Control } & \multicolumn{2}{|c|}{ ANOVA } \\
\hline & & \multirow{2}{*}{$\begin{array}{c}\begin{array}{c}\text { Before } \\
\text { antioxidant } \\
\text { drugs }\end{array} \\
3.858 \pm 2.320\end{array}$} & \multirow{2}{*}{$\begin{array}{c}\begin{array}{c}\text { After } \\
\text { antioxidant } \\
\text { drugs }\end{array} \\
2.362 \pm 1.086 \\
\end{array}$} & & $\begin{array}{c}F \\
\text { test }\end{array}$ & $\begin{array}{c}\mathbf{P} \\
\text { value }\end{array}$ \\
\hline IL-1B (ng/ml) & $\begin{array}{c}\text { Mean } \pm \\
\text { SD }\end{array}$ & & & $\begin{array}{l}0.867 \pm \\
0.072 \\
\end{array}$ & 35.745 & $<0.001 *$ \\
\hline \multirow{2}{*}{$\begin{array}{c}\text { Paired Samples } \\
\text { Test }\end{array}$} & $\mathbf{t}$ & \multicolumn{2}{|c|}{7.060} & & & \\
\hline & P-value & \multicolumn{2}{|c|}{$<0.001 *$} & & & \\
\hline MDA (umol/L) & $\begin{array}{c}\text { Mean } \pm \\
\text { SD }\end{array}$ & $2.501 \pm 0.597$ & $2.052 \pm 0.377$ & $\begin{array}{c}0.808 \pm \\
0.204\end{array}$ & 149.431 & $<0.001 *$ \\
\hline \multirow{2}{*}{$\begin{array}{c}\text { Paired Samples } \\
\text { Test } \\
\end{array}$} & $\mathbf{t}$ & \multicolumn{2}{|c|}{10.536} & & & \\
\hline & P-value & \multicolumn{2}{|c|}{$<0.001 *$} & & & \\
\hline TBARS (pg/ml) & $\begin{array}{c}\text { Mean } \pm \\
\text { SD }\end{array}$ & $3.277 \pm 0.691$ & $2.599 \pm 0.264$ & $\begin{array}{l}1.833 \pm \\
0.200\end{array}$ & 93.466 & $<0.001 *$ \\
\hline \multirow{2}{*}{$\begin{array}{c}\text { Paired Samples } \\
\text { Test }\end{array}$} & $\mathbf{t}$ & \multicolumn{2}{|c|}{9.121} & & & \\
\hline & P-value & \multicolumn{2}{|c|}{$<0.001^{*}$} & & & \\
\hline TNF- $\alpha(n g / m l)$ & $\begin{array}{c}\text { Mean } \pm \\
\text { SD }\end{array}$ & $3.666 \pm 1.263$ & $2.577 \pm 0.420$ & $\begin{array}{c}0.922 \pm \\
0.252 \\
\end{array}$ & 109.138 & $<0.001 *$ \\
\hline \multirow{2}{*}{$\begin{array}{c}\text { Paired Samples } \\
\text { Test }\end{array}$} & $\mathbf{t}$ & \multicolumn{2}{|c|}{7.385} & & & \\
\hline & P-value & \multicolumn{2}{|c|}{$<0.001 *$} & & & \\
\hline
\end{tabular}

Abbreviations; IL-1B=interleukin 1 $\beta$, MDA=malondialdehyde, $\mathbf{T B A R S}=$ thiobarbituric acid reactive substance, $\mathbf{T N F}-\boldsymbol{\alpha}=$ tumor necrosis factor alpha, $\mathbf{S D}=$ standard deviation, $\mathbf{t}=$ student test.

- As regards to parathyroid hormone level, there was significant increase in patients level in comparison to controls ( $\mathrm{p}$ value<0.001) [figure 1].

- As regard interleukin $1 \beta$ level, there was significant increase in level of IL-1B in patients before giving antioxidant drugs when compared with that level 3 months after giving drugs(p value $<0.001)$, also there was significant increase in level of IL-1B in patients before and after giving drugs when compared with controls( $\mathrm{p}$ value <0.001) [figure 2].

- As regard blood pressure, there were no statistically significant differences between the systolic blood pressure and diastolic blood pressure in the studied patients before and after giving antioxidant drugs(pvalue $>0.05$ ) but there were significant increase in the systolic and diastolic blood pressure of patients before and after giving drugs when compared with controls(p-value<0.001) [figure 3].

- As regard thiobarbituric acid reactive substances level, there was significant increase in level of TBARS in patients before giving antioxidant drugs when compared with that level 3 months after giving drugs(p value $<0.001$ ), also there was significant increase in level of TBARS in patients before and after giving drugs when compared with controls( $\mathrm{p}$ value $<0.001)$ [figure 4]. 


\section{Ahmed Odima et al.}

- As regard tumor necrosis factor alpha level, there was significant increase in level of TNF- $\alpha$ in patients before giving antioxidant drugs when compared with that level 3 months after giving drugs( $\mathrm{p}$ value<0.001),also there was significant increase in level of TNF- $\alpha$ in patients before and after giving drugs when compared with controls ( $p$ value $<0.001$ ) [figure 5].

- As regard malondialdehyde level (MDA), there was significant increase in level of MDA in patients before giving antioxidant drugs when compared with that level 3 months after giving drugs( $p$ value $<0.001)$, also there was significant increase in level of MDA in patients before and after giving drugs when compared with controls $(\mathrm{p}$ value $<0.001)$ [figure 6 ].

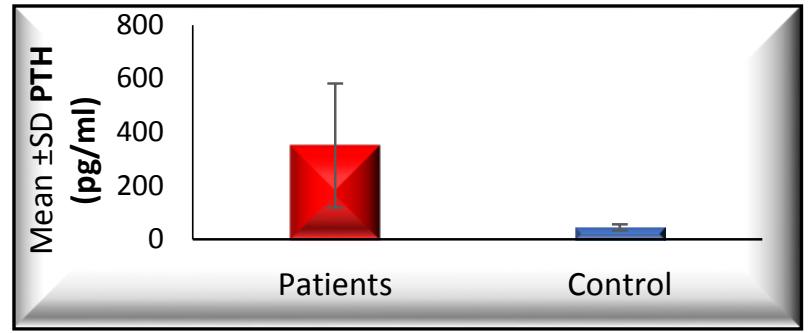

Figure (1): Correlation between PTH (parathyroid hormone level) level in patients and controls.

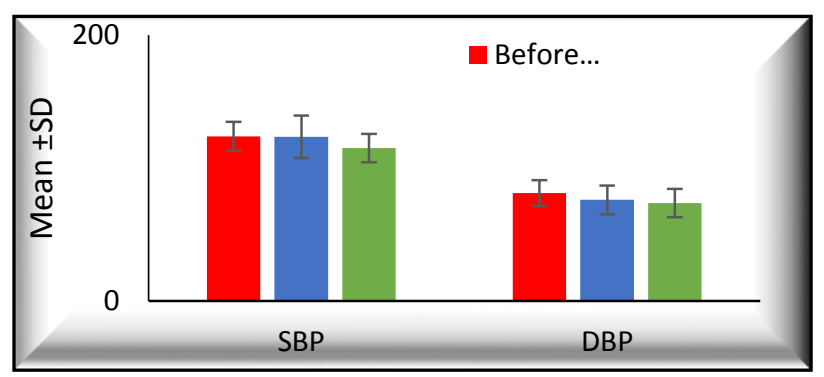

Figure (3): Correlation between systolic and diastolic blood pressure of patients before and 3 months after giving antioxidant drugs and controls.

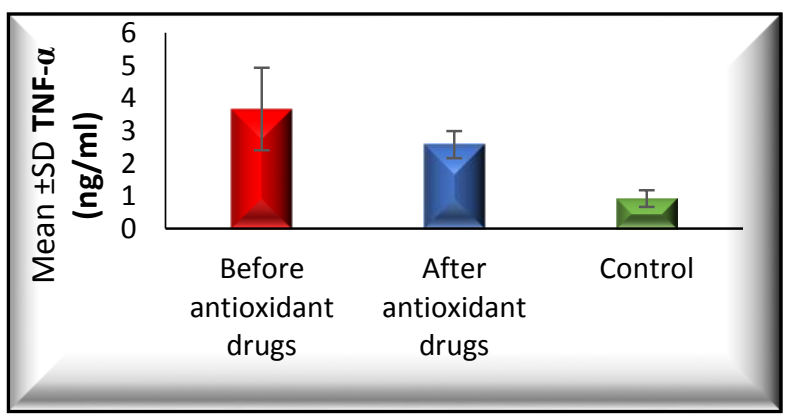

Figure (5): Correlation between level of TNF- $\alpha$

(tumor necrosis factor alpha level) in patients before and 3 months after giving antioxidant drugs and controls.

- As regard correlation between different parameter used in theses study; there was significant negative correlation between [IL-1B level before treatment by antioxidant drugs and age (figure7), MDA level before treatment by antioxidant drugs and blood urea level (figure8), MDA level and blood urea level after treatment (figure9), TBARS level before treatment by antioxidant drugs and age (figure10), TBARS level and age after treatment (figure11), TNF- $\alpha$ level before treatment by antioxidant drugs and age (figure12) and TNF- $\alpha$ level and age after treatment (figure13)]. while the correlation was significantly positive between [MDA and IL-1B before treatment (figure14), TBARS and IL-1B before treatment (figure16), TNF- $\alpha$ and IL-1B before treatment(figure18), TBARS and MDA before treatment(figure20), TNF- $\alpha$ and MDA before treatment 


\section{Ahmed Odima et al.}

(figure22), TNF- $\alpha$ and TBARS before treatment (figure24), MDA and IL-1B after treatment (figure15), TBARS and IL-1B after treatment (figure17), TNF- $\alpha$ and IL-1B after treatment (figure19), TBARS and MDA after treatment (figure21), TNF- $\alpha$ and MDA after treatment (figure23) and TNF- $\alpha$ and TBARS after treatment (figure25)].

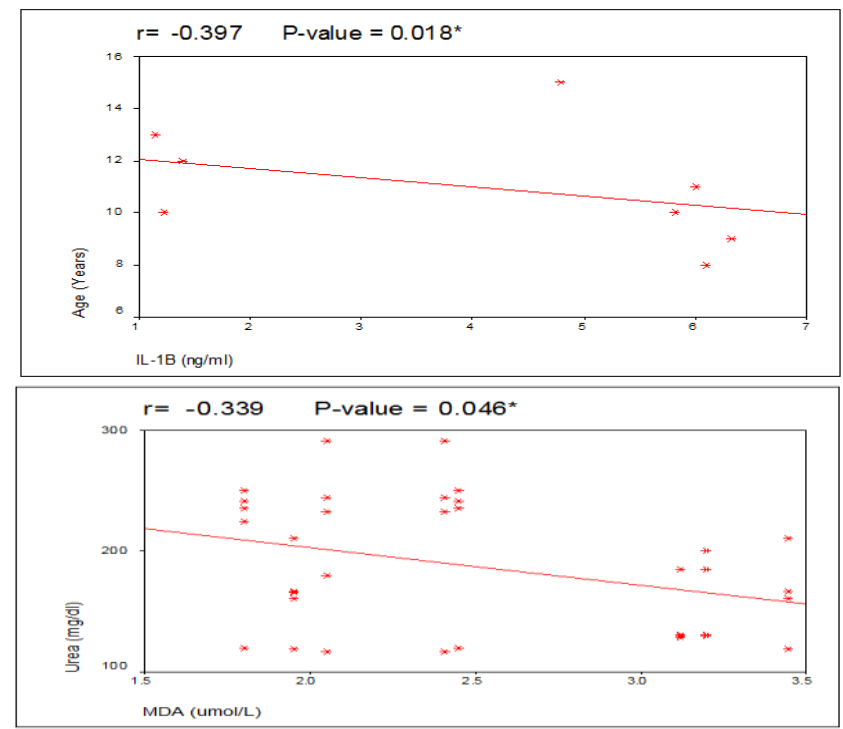

Figure (8): Correlation between malondialdehyde (MDA) level of patients before treatment by antioxidant drugs and blood urea level

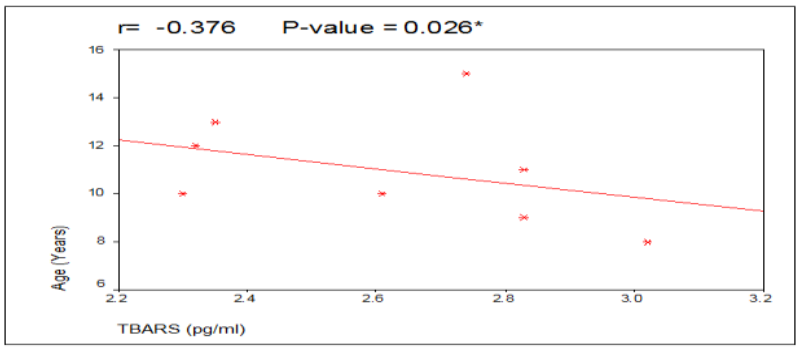

Figure (10): Correlation between thiobarbituric acid reactive substances (TBARS) level of patients before treatment by antioxidant drugs and age
Figure (7): Correlation between interleukin $1 \beta$ (IL-1 $\beta$ ) level of patients before treatment by antioxidant drugs and age.

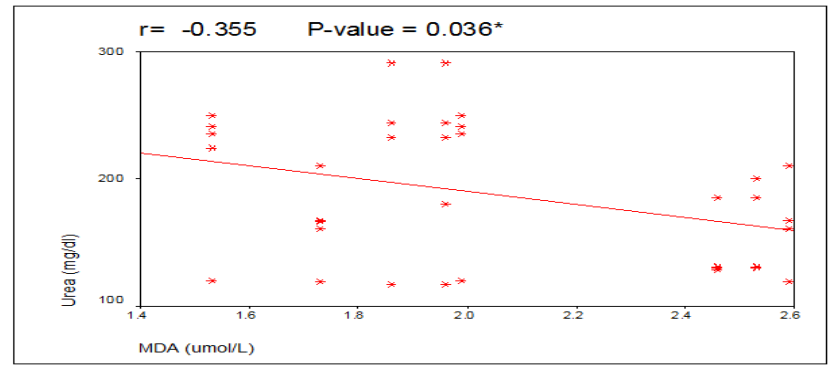

Figure (9): Correlation between malondialdehyde (MDA) level of patients after treatment by antioxidant drugs and blood urea level.

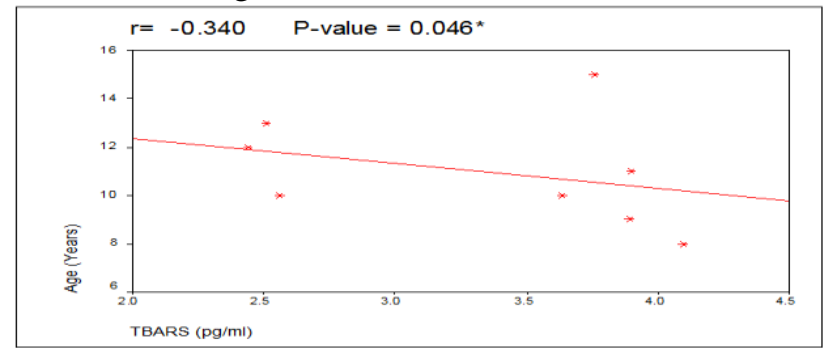

Figure (11): Correlation between thiobarbituric acid reactive substances (TBARS) level of patients after treatment by antioxidant drugs and age. 
Ahmed Odima et al.

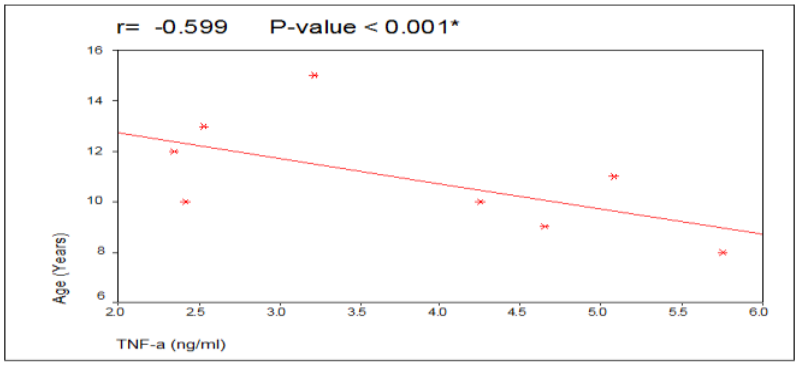

Figure (12): Correlation between tumor necrosis factor alpha (TNF- $\alpha$ ) level of patients before treatment by antioxidant drugs and age

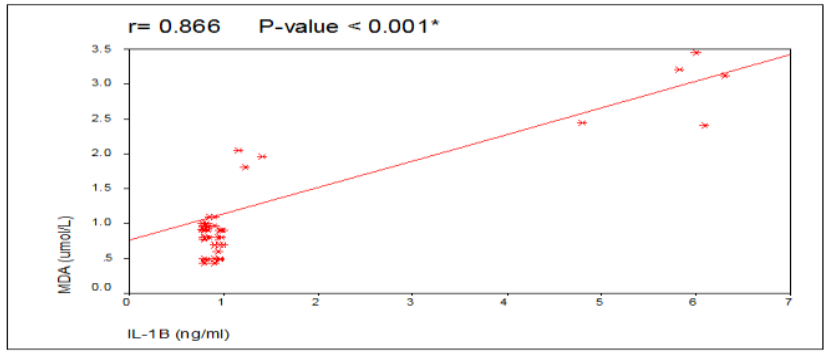

Figure (14): Correlation between MDA level and IL-1B level before giving antioxidant drugs.

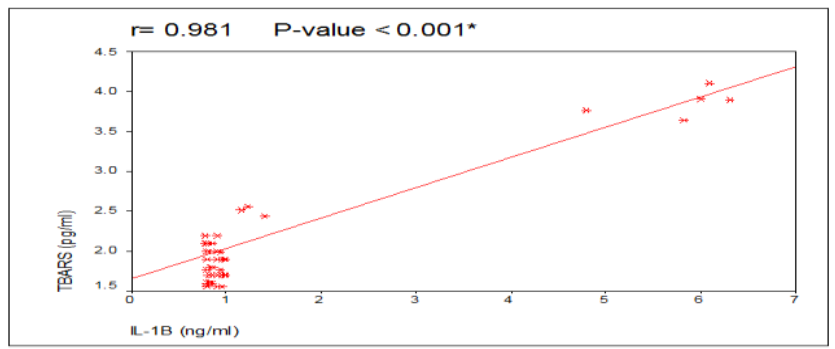

Figure (16): Correlation between TBARS level and IL-1B level before giving antioxidant drugs.

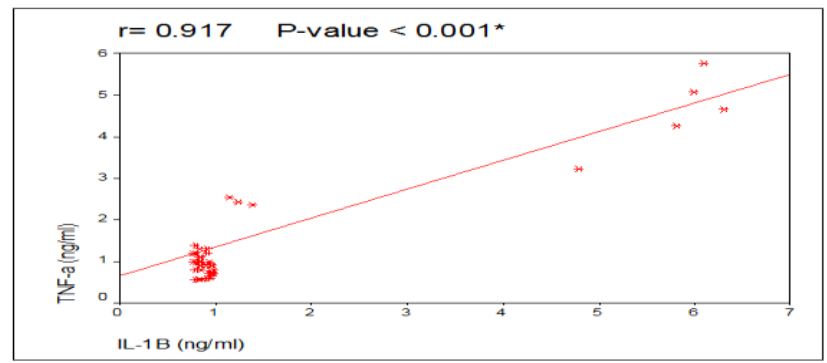

Figure (18): Correlation between TNF- $\alpha$ level and IL-1B level before giving antioxidant drugs.

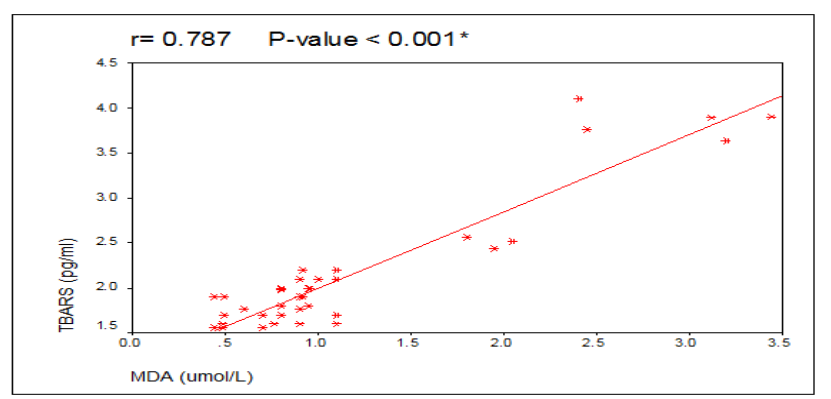

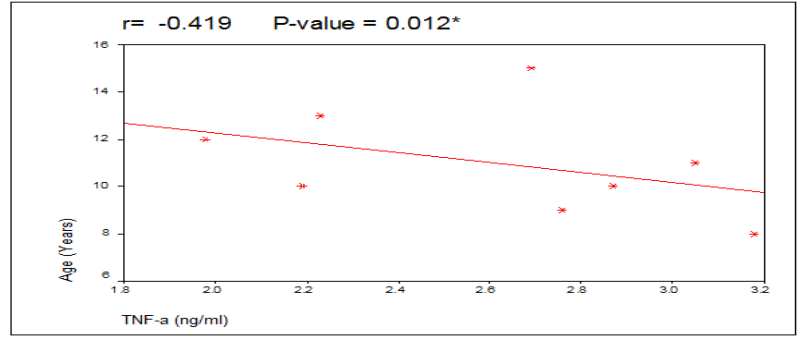

Figure (13): Correlation between tumor necrosis factor alpha (TNF- $\alpha$ ) level of patients after treatment by antioxidant drugs and age.

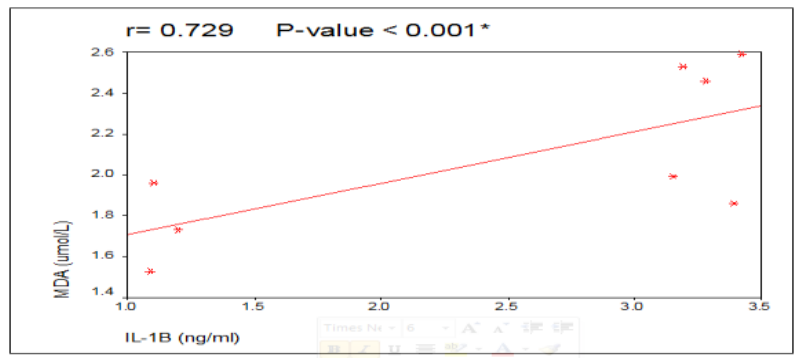

Figure (15): Correlation between MDA level and IL-1B level after giving antioxidant drugs.

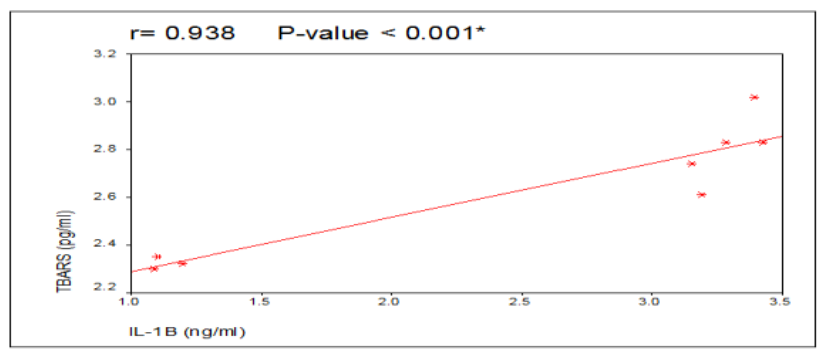

Figure (17): Correlation between TBARS level and IL-1B level after giving antioxidant drugs.

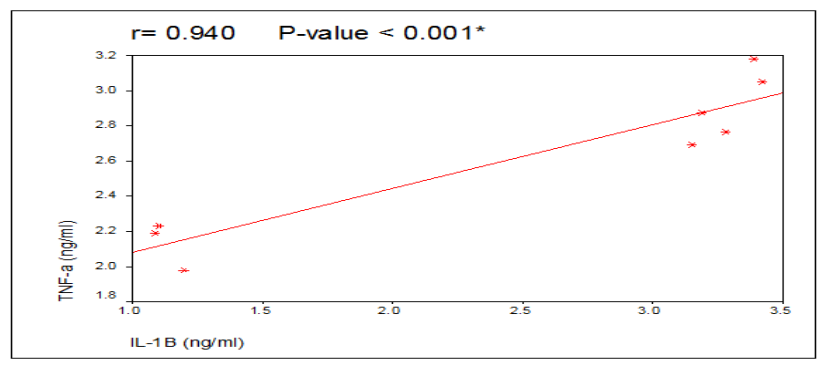

Figure (19): Correlation between TNF- $\alpha$ level and IL-1B level after giving antioxidant drugs.

Figure (20): Correlation between TBARS level and MDA level before giving antioxidant drugs. 
The study of oxidative status in children with....
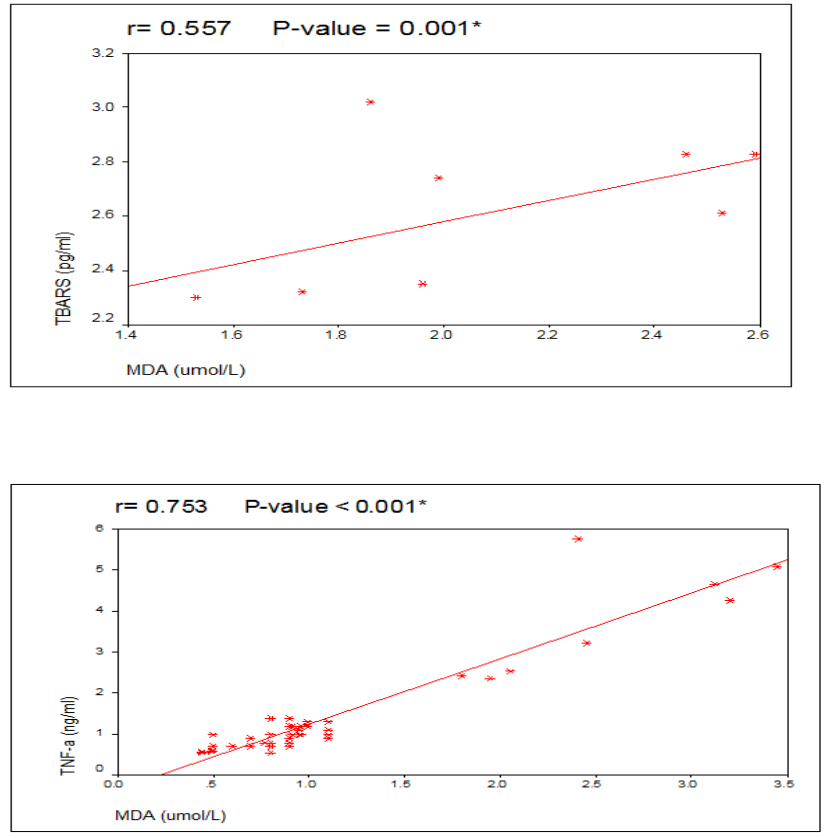

Figure (22): Correlation between TNF- $\alpha$ level and MDA level before giving antioxidant drugs.

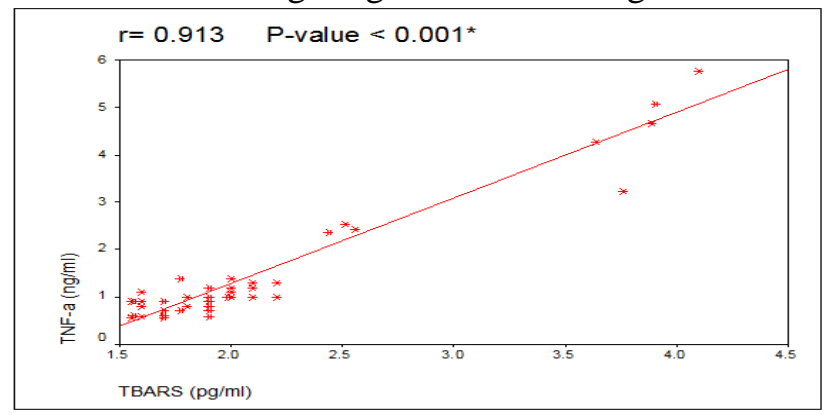

Figure (24): Correlation between TNF- $\alpha$ level and TBARS level before giving antioxidant drugs.

\section{DISCUSSION}

Chronic uremia is considered a proinflammatory state associated with high morbidity and mortality ${ }^{(10)}$. Patients on regular hemodialysis have elevated oxidative stress compared to healthy matched controls. Oxidative stress may be increased because of loss of antioxidants during dialysis (11), interaction between blood and dialysis membrane ${ }^{(\mathbf{1 2})}$, bacterial products in dialysate crossing the dialysis membrane directly or indirectly stimulating release of reactive species by neutrophils and malnutrition decreasing the uptake of dietary antioxidants ${ }^{(13)}$. On the basis of the evidence of elevated oxidative stress in pre-dialysis chronic kidney disease patients, it is evident that the disease itself contributes to this state ${ }^{(\mathbf{1 4})}$. Patients treated by renal replacement therapy are subjected to a wide range of biochemical disorders, some of which were ascribed to increased oxidative stress ${ }^{(15)}$.
Figure (21): Correlation between TBARS level and MDA level after giving antioxidant drugs.

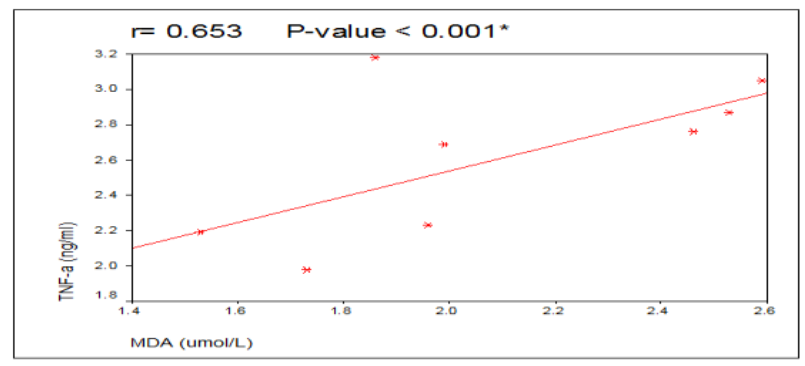

Figure (23): Correlation between TNF- $\alpha$ level and MDA level after giving antioxidant drugs.

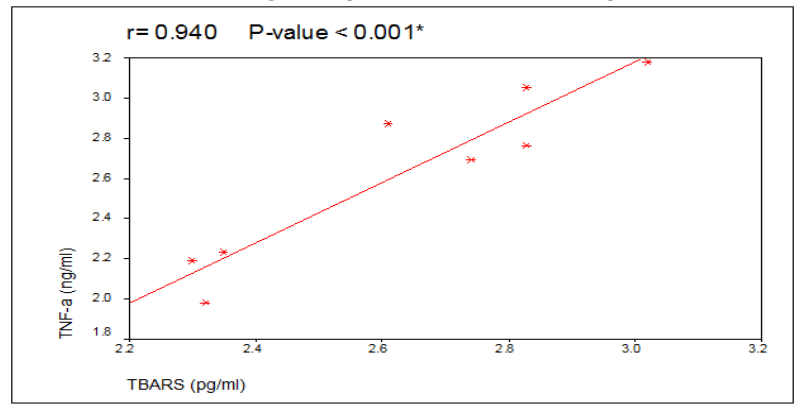

Figure (25): Correlation between TNF- $\alpha$ level and TBARS level after giving antioxidant drugs.

El shamaa et al. ${ }^{(16)}$ studied that pediatric patients with end-stage renal disease undergoing hemodialysis are exposed to oxidative stress associated with an impairment of antioxidant defense and an overproduction of oxidative stress markers and they approved that oxidative stress plays a significant role in the development of inflammation in those patients.

There is currently a great interest in the assessment of antioxidant status as antioxidant depletion may contribute to a number of diseases including ESRD. In the current study, alphatochopherol (vitamin E), N-acetyl cysteine and vitamin c were used as antioxidant drugs. This is in agreement with Coombes et al. ${ }^{(9)}$ who used them in doses of $5 \mathrm{mg} / \mathrm{kg} / \mathrm{day}$ for vitamin $\mathrm{E}$, vitamin $\mathrm{C}$ in a dose of 100-200 mg /day and N-Acetyl Cysteine in a dose of one sachet $(200 \mathrm{mg})$ twice daily with meal.

In agreement with $\boldsymbol{E l}$ shamaa et al. ${ }^{(16)}$ the current study showed that there were no significant 
differences between the studied groups regarding age or sex. The mean age of patients in years was $11.057 \pm 2.100$ while that of control group was $10.971 \pm 2.294$. There were no significant differences between studied patients and controls as regards weight and height. The mean weight for patients was $29.510 \pm 9.541 \mathrm{~kg}$ while that of control group was $31.140 \pm 10.719 \mathrm{~kg}$. The mean height for patients was $128.110 \pm 10.154 \mathrm{~cm}$ while that of control group was $130.331 \pm 15.814 \mathrm{~cm}$. In the current study $40 \%$ of patients were male while $60 \%$ of patients were female. This ratio is in agreement with Shiba et al. ${ }^{(17)}$ and disagree with other studies in which the majorities were boys. For example, Jamro et al. ${ }^{(\mathbf{1 8})}$, where seventy eighty confirmed cases of chronic renal failure (CRF) were included in the study. Out of them 51 were male and 29 females (M: F ratio 1.8:1). Also, in another study done by Rahman et al. ${ }^{(19)}$ a total of 44 children with CRF having mean age of $8.73 \pm$ 3.56 years old were diagnosed during study period, 30 cases $(68.19 \%)$ were males and 14 cases $(31.81 \%)$ were females.

Also, Lewis et al. ${ }^{(20)}$ found that chronic renal failure more common in males than females due to predominance of males in renal dysplasia and obstructive uropathy that leads to renal failure. This difference in ratio may be due to the more interest of the Egyptian people for males than females who seek renal transplantation earlier than females.

In the current study, the etiologies of renal failure were congenital anomalies of kidney and urinary tract in $57.14 \%$ of cases, lupus nephritis in $22.86 \%$ of cases, steroid resistant nephrotic syndrome in $11.43 \%$ of cases and hemolytic uremic syndrome in $8.57 \%$ of cases. The National

Kidney Foundation ${ }^{(21)}$ reported that from birth to age 4 years, birth defects and hereditary diseases are by far the leading causes of kidney failure. Between ages 5 and 14 years, hereditary diseases continue to be the most common causes, followed closely by glomerular diseases. In the 15- to 19years-old group, glomerular diseases are the leading cause, and hereditary diseases become rare.

In our study, the mean value of hemoglobin level for control group was statistically and significantly higher compared to patients. Similar results were published by Clermont et al. ${ }^{(22)}$ who noted that chronic renal failure patients were anemic compared to healthy controls. Mean value of total leucocytic count for control group was significantly higher compared to patients. Mean value of platelets count for control group was statistically higher compared with patients. Mean values of serum albumin level in control group was significantly higher compared to patients. There were an increased concentrations of both urea, creatinine and blood urea nitrogen of patients compared to control group. This is in line with findings previously published ${ }^{(22,23,15}$ and 24).

There was an increased level of parathyroid hormone in patients compared to control group, this might be attributed to chronic kidney disease and MBD (mineral and bone disorders) in which there is an increased retention of phosphorus. The current result was in agreement with Kawaguchi et al. ${ }^{(25)}$, Malyszko et al. ${ }^{(26)}$ and Jacobson et al. ${ }^{(27)}$.

As regards blood pressure, there were no statistically significant differences between the systolic blood pressure and diastolic blood pressure in the studied patients before and after giving antioxidant drugs ( $\mathrm{p}$ value $>0.05$ ) but there were significant increase in the systolic and diastolic blood pressure of patients before and after giving drugs when compared to controls ( $\mathrm{p}$ value $<0.001$ ).

In the current study, a significant increase in the level of serum interleukin $1 \beta$, malondialdehyde, thiobarbituric acid reactive substances, tumor necrosis factor alpha levels in patients before giving antioxidant drugs when compared to these levels 3 months after giving antioxidant drugs. These results can be attributed to the increased oxidative stress in patients with ESRD. These results were in agreement with Penuchant et al. ${ }^{(28)}$ and Jackson et al. ${ }^{(29)}$ who studied oxidative stress markers in children with ESRD, they concluded that there was an increase in oxidative stress in children on maintenance dialysis. This could be attributed to the highly reduced activity of the enzymatic antioxidant defense system in plasma of pediatric dialysis patients. In addition, there was significant increase in the levels of these indices in patients before and after giving antioxidant drugs when compared to control group. This is consistent with findings previously published by Elshamaa et al. ${ }^{(15)}$ and Samouilidou et al. ${ }^{(30)}$ who studied oxidative stress markers and $\mathrm{C}$ - reactive protein in pediatric patients on hemodialysis and found that total antioxidant capacity and MDA levels were significantly higher in children on HD than in the healthy controls. They concluded that there was an increase in oxidative stress in children on HD and that the susceptibility to oxidative stress is strongly related to the level of MDA produced in plasma. There was a significant increase in interleukin $1 \beta$ and tumor necrosis factor alpha levels of patients 
when compared to control group. This is in agreement with Ghobrial et al. ${ }^{(31)}$ who studied oxidative stress in Egyptian hemodialysis children and found that serum level of TNF- $\alpha$ and IL- $1 \beta$ were significantly higher in children on hemodialysis as compared to the control group. They concluded that the levels of cytokines are high in pediatric patients on hemodialysis, which reflects a state of oxidative stress.

The current study also showed a significant increase in level of malondialdehyde level of patients when compared to control group. This is in agreement with Z $\mathbf{w o l i n s k a}$ et al. ${ }^{(32)}$ who studied lipid peroxidation and antioxidant enzymes in children on dialysis. They reported that the erythrocyte MDA concentrations in ESRD children were significantly higher than in healthy subjects.

In the current study, there was significant increase in lipid peroxidation represented by thiobarbituric acid reactive substances in patients when compared to control group. This is in agreement with Toborek et al. ${ }^{(33)}$ who studied effect of hemodialysis on lipid peroxidation and antioxidant system in patients with chronic renal failure. They found that hemodialysis produce increased lipid peroxidation.

As regards correlations between indices of oxidative stress and different studied demographic and laboratory data, there was significant negative correlation between TNF- $\alpha$, IL- $1 \beta$ and TBARS levels of patients before treatment by antioxidants drugs and age. There was a significant negative correlation between TNF- $\alpha$ and TBARS levels of patients after treatment by antioxidant drugs and age. There was significant negative correlation between MDA level of patients before \& after treatment by antioxidant drugs and blood urea level. There was a significant positive correlation REFERENCES

1. Mortazavi F, Rafiee A (2010): Etiology of pediatric chronic kidney diseases in north-west of Iran. Pakistan Journal of Biological Sciences, 13(9): 456.

2. National Institute of Diabetes, Digestive, Kidney Diseases (2005): Division of Kidney, Urologic, Hematologic Diseases, Urban Institute. https://www.niddk.nih.gov, About NIDDK > Offices \& Divisions

3. Lotfy H, Sabry S, Ghobrial, E, Abed S (2015): The effect of regular hemodialysis on the nutritional status of children with end-stage between MDA, TBARS and TNF- $\alpha$ levels of patients before treatment by antioxidant drugs and IL-1 $\beta$ level. There was significant positive correlation between TBARS and TNF- $\alpha$ levels of patients before treatment by antioxidant drugs and MDA level. There was significant positive correlation between TBARS and TNF- $\alpha$ levels of patients after treatment by antioxidant drugs and IL-1 $\beta$ level. There was significant positive correlation between TBARS and TNF- $\alpha$ levels of patients after treatment by antioxidant drugs and MDA level. There was significant positive correlation between TNF- $\alpha$ level of patients before $\&$ after treatment by antioxidant drugs and TBARS level. There were no available comparable data in previously published articles on pediatric patients with ESRD on regular hemodialysis.

In conclusion the current study showed an increase in markers of oxidative stress in children with end-stage renal disease on regular hemodialysis in the form of:

-Increase serum level of interleukin $1 \beta$ (IL-1 $\beta$ ).

- Increased serum level of tumor necrosis factor alpha (TNF- $\alpha$ ).

- Increased serum level of thio-barbituric acid reactive substances (TBARS).

- Increased serum level of malondialdehyde (MDA).

These oxidative stress markers were decreased after regular therapy by antioxidant medications for 3 months in the form of vitamin $\mathrm{E}$ (5 $\mathrm{mg} / \mathrm{kg} /$ day), vitamin C (100-200 mg /day) and NAcetyl Cysteine ( one sachet $200 \mathrm{mg}$ twice daily with meal). Therefore, supplementation of antioxidant vitamins is required as an adjuvant therapy in children with end stage renal disease and children with chronic renal failure on regular hemodialysis.

renal disease. Saudi Journal of Kidney Diseases and Transplantation, 26(2): 263.

4. Sokol R Hoffenberg E (1996): Antioxidants in pediatric gastrointestinal disease. Pediatric Clinics, 43(2): 471-488.

5. Schreck R, Albermann $K$, Baeuerle $P$ (1992): Nuclear factor $k B$ : an oxidative stressresponsive transcription factor of eukaryotic cells (a review). Free radical research communications, 17(4): 221-237.

6. Gwinner W, Gröne H (2000): Role of reactive oxygen species in glomerulonephritis. 
Nephrology Dialysis Transplantation, 15(8): 1127-1132.

7. Bulucu F, Vural A, Aydin A et al. (2000): Oxidative stress status in adults with nephrotic syndrome. Clinical nephrology, 53(3): 169-173.

8. Pergola P, Krauth M, Huff J et al. (2011): Effect of bardoxolone methyl on kidney function in patients with T2D and stage 3b-4 CKD. American journal of nephrology, 33(5):469-476.

9. Coombes J, Fassett R (2012): Antioxidant therapy in hemodialysis patients: a systematic review. Kidney international, 81(3): 233-246.

10. Stompór T, Pasowicz M, Sułowicz W et al. (2003): An association between coronary artery calcification score, lipid profile, and selected markers of chronic inflammation in ESRD patients treated with peritoneal dialysis. American Journal of Kidney Diseases, 41(1): 203-211.

11. Ha T, Sattar N, Talwar D, Cooney J et al. (1996): Abnormal antioxidant vitamin and carotenoid status in chronic renal failure. QJM: An International Journal of Medicine, 89(10): 765-770.

12. Cheung A (1990): Biocompatibility of hemodialysis membranes. Journal of the American Society of Nephrology, 1(2): 150-161.

13. Hu M, Louie S, Cross C, Motchnik P et al. (1993): Antioxidant protection against hypochlorous acid in human plasma. The Journal of laboratory and clinical medicine, 121(2):257-262.

14. Oberg B, McMenamin E, Lucas F et al. (2004). Increased prevalence of oxidant stress and inflammation in patients with moderate to severe chronic kidney disease. Kidney international, 65(3), 1009-1016.

15. Antolini F, Valente F, Ricciardi D et al. (2005): Principal component analysis of some oxidative stress parameters and their relationships in hemodialytic and transplanted patients. Clinica chimica acta, 358(1-2),:87-94.

16. Elshamaa M, Sabry S, Nabih $M$ et al. (2009):Oxidative stress markers and $C$-reactive protein in pediatric patients on hemodialysis. Annals of Nutrition and Metabolism, 55(4):309316.

17. Ghobrial E, Mahfouz N, Fathy G et al. (2013). Oxidative stress in Egyptian hemodialysis children. Iranian journal of kidney diseases, 7(6): 485 .

18. Jamro S, Channa N, Shaikh A et al. (2003): Chronic renal failure in children. JPMA. The
Journal of the Pakistan Medical Association, 53(4): 140-142.

19. Rahman M, Karim M, Hoque E et al. (2005): Chronic renal failure in children. Mymensingh medical journal: MMJ., 14(2): 156-159.

20. Lewis M, Shaw J, Reid C et al. (2007): https://www.ncbi.nlm.nih.gov/pmc/articles/PM C4777794/

21. National KF (2006): KDOQI clinical practice guidelines and clinical practice recommendations for anemia in chronic kidney disease. American journal of kidney diseases: the official journal of the National Kidney Foundation, 47(3): S11.

22. Clermont $G$, Lecour $S$, Lahet $J$ et al. (2000): Alteration in plasma antioxidant capacities in chronic renal failure and hemodialysis patients: a possible explanation for the increased cardiovascular risk in these patients. Cardiovascular Research, 47(3): 618-623.

23. Montini G, Pisanello L, Testa S et al. (2003): Urea percentiles in children with chronic renal failure. Pediatric Nephrology, 18(3): 261265.

24. Ajala M, Ogunro P, Odun A (2011): Effect of hemodialysis on total antioxidant status of chronic renal failure patients in government hospitals in Lagos Nigeria. Nigerian journal of clinical practice, 14(2): 154-158.

25. Kawaguchi M, Yamada $M$, Wada $\mathrm{H}$ et al. (1992): Roles of active oxygen species in glomerular epithelial cell injury in vitro caused by puromycin aminonucleoside. Toxicology, 72(3): 329-340.

26. Malyszko J, Malyszko J, Mysliwiec M (2001). Comparison of hemostatic disturbances between patients on CAPD and patients on hemodialysis. Peritoneal dialysis international, 21(2), 158165.

27. Jacobson S, Egberg N, Hylander B et al. (2002): Correlation between soluble markers of endothelial dysfunction in patients with renal failure. American journal of nephrology, 22(1): 42-47.

28. Peuchant E, Carbonneau M, Dubourg L et al. (1994): Lipoperoxidation in plasma and red blood cells of patients undergoing haemodialysis: vitamins $A, E$, and iron status. Free Radical Biology and Medicine, 16(3):339346.

29. Jackson P, Loughrey C, Lightbody J et al. (1995): Effect of hemodialysis on total antioxidant capacity and serum antioxidants in 
patients with chronic renal failure. Clinical chemistry, 41(8): 1135-1138.

30. Samouilidou E, Grapsa E (2003): Effect of dialysis on plasma total antioxidant capacity and lipid peroxidation products in patients with endstage renal failure. Blood purification, 21(3): 209-212.

31. Ghobrial E, Mahfouz N, Fathy G et al. (2013):Oxidative stress in Egyptian hemodialysis children. Iranian journal of kidney diseases, 7(6): 485.
32. Zwolińska D, Grzeszczak W, Szczepańska M et al. (2006): Lipid peroxidation and antioxidant enzymes in children on maintenance dialysis. Pediatric Nephrology, 21(5): 705.

33. Toborek M, Wasik T, Drózdz M et al. (1992):Effect of hemodialysis on lipid peroxidation and antioxidant system in patients with chronic renal failure. Metabolism-Clinical and Experimental, 41(11), 1229-1232. 